\title{
¿DIOS CAMBIÓ DE SEXO? EL DEBATE INTERNACIONAL SOBRE LA FEMINIZACIÓN DE LA RELIGIÓN Y ALGUNAS REFLEXIONES PARA LA ESPAÑA DECIMONÓNICA
}

\author{
DID GOD CHANGE SEX? THE INTERNATIONAL DEBATE \\ ABOUT THE FEMINIZATION OF RELIGION AND SOME \\ REFLECTIONS FOR THE 19TH CENTURY SPAIN
}

\author{
Raúl Mínguez Blasco \\ Universidad del País Vasco/Euskal Herriko Unibertsitatea ${ }^{1}$
}

Entregado el 9-1-2015 y aceptado el 4-6-2015.

\begin{abstract}
Resumen: Este artículo pretende ofrecer una aproximación crítica al debate internacional en torno a la feminización de la religión durante el siglo XIX y principios del xx. Se recogen las principales aportaciones de los autores que han trabajado sobre esta cuestión, desde los inicios de la tesis de la feminización religiosa a mediados de los setenta hasta los desarrollos más recientes marcados por el giro discursivo y el énfasis sobre la masculinidad y las actividades religiosas de los hombres. También se hace referencia a las contribuciones más destacadas de la historiografía española y se reflexiona sobre futuras vías de inves-
\end{abstract}

${ }^{1}$ El presente trabajo se inscribe dentro del grupo de investigación La experiencia de la sociedad moderna en España, 1870-1990, de la Universidad del País Vasco UPV/EHU, financiado por GIU11/22 y el proyecto del MICINN código: HAR2012-37959-C02-01. El autor también forma parte del proyecto HAR2014-53802-P, financiado por el MINECO. La publicación de este trabajo ha sido posible gracias a un contrato de investigación de carácter postdoctoral concedido en el marco de la convocatoria de ayudas para la especialización de personal investigador doctor del Vicerrectorado de Investigación de la UPV/EHU de 2014. Agradezco a Inmaculada Blasco y a Nerea Aresti sus oportunas reflexiones y recomendaciones bibliográficas a la hora de preparar este artículo. 
tigación. Las relevantes conexiones entre la tesis de la feminización religiosa y la tesis de la secularización además de la relación conflictiva entre la religión y la modernidad están presentes a lo largo del trabajo.

Palabras clave: Feminización de la religión, género, discurso, masculinidad, secularización, modernidad.

\begin{abstract}
The aim of this article is to introduce critically the international debate about the feminization of religion during the $19^{\text {th }}$ century and the first decades of the $20^{\text {th }}$ century. The main contributions of the scholars who have dealt with this matter are explained in this article, ranging from the beginnings of the feminization thesis in the middle of the seventies to the most recent research influenced by the discursive turn and the emphasis in masculinity and the religious activities of men. Furthermore, the most outstanding contributions of the Spanish historiography and some reflections about future research lines are taken into account. The relevant links among the feminization thesis and the secularization thesis as well as the troubled relation between religion and modernity are present along the article.
\end{abstract}

Key words: Feminization of religion, gender, discourse, masculinity, secularization, modernity. 
«Dieu changea de sexe, il faut le dire encore une fois». Estas fueron las palabras literales escritas por Jules Michelet en un periódico francés en 1843. Este republicano anticlerical, que poco tiempo después publicaría su Du prête, de la femme, de la famille, reflejó como pocos los miedos y temores de gran parte del anticlericalismo europeo a lo que se percibió como una estrecha alianza entre las mujeres y la Iglesia. En su opinión, el principal peligro se encontraba en el sacerdote, «nacido hombre y fuerte, pero que le conviene hacerse el débil, parecerse a la mujer», ${ }^{2}$ por su capacidad de influencia sobre las mujeres en el confesionario y por entrometerse así en la vida familiar. Resulta curioso que el publicista ultramontano Louis Veuillot, a pesar de las obvias diferencias políticas e ideológicas que le separaban de su coetáneo Michelet, compartiera con él la idea de que en el siglo XIX la religión y, en concreto el catolicismo, se declinase cada vez más con nombre de mujer. «La época que siguió al siglo de Voltaire podrá llamarse el siglo de María», llegó a escribir el periodista francés. ${ }^{3}$ Así pues, ya fuera connotada de manera positiva o negativa, lo que es evidente es que durante el siglo XIX estuvo muy extendida la idea de que la religión se encontraba inmersa en un proceso de feminización. Aunque han pasado muchos años desde entonces, los antropólogos, sociólogos e historiadores que nos hemos aproximado a esta cuestión tenemos ciertas dificultades en desprendernos de algunos de los prejuicios y estereotipos procedentes de aquella época.

Más que un estado de la cuestión al uso, este artículo se concibe como un ensayo historiográfico cuyo principal objetivo es realizar un análisis crítico de la ya larga trayectoria de lo que los especialistas han denominado tesis de la feminización religiosa. ${ }^{4}$ Según dicha teoría, el cristianismo decimonónico adquirió un carácter más femenino que en

2 Jules Michelet, El sacerdote, la mujer y la familia (traducción de A. Abella), Jané Hermanos, Barcelona, s.f., pp. XIV-XV.

${ }^{3}$ Tanto la cita de Michelet con la que comienza el artículo como estas palabras de Veuillot aparecen recogidas en Stéphane Michaud, Muse et madone. Visages de la femme de la Révolution française aux apparitions de Lourdes, Seuil, Paris, 1985, pp. 20 y 17 respectivamente.

${ }^{4}$ Otros balances historiográficos que sobre este tema se han realizado en otras historiografías nacionales son Bernhard Schneider: «Feminisierung der Religion im 19. Jahrhundert. Perspektiven einer These im Kontext des deutschen Katholizismus», Trierer Theologische Zeitschrift, 111, 2002, pp. 123-147 y Tine van Osselaer y Thomas Buerman: «Feminization Thesis: A Survey of International Historiography and a Probing of Belgian Grounds», Revue d'histoire ecclésiastique, 103, 2008, pp. 497-544. 
siglos anteriores como consecuencia de diversos fenómenos asociados: el aumento de la práctica religiosa entre las mujeres, el incremento del número de mujeres en el seno de la estructura eclesiástica, la presencia de una piedad que adquirió rasgos considerados femeninos y la vinculación discursiva de las mujeres con la religión. A pesar de que el protestantismo, a diferencia del catolicismo, no contó en su imaginario con figuras tan potentes como la de la Virgen María, también se ha incluido dentro de la tesis de la feminización porque experimentó fenómenos tan interesantes como, por ejemplo, el surgimiento del diaconado femenino. La feminización religiosa ha adquirido un amplio consenso en la historiografía por su atrayente capacidad explicativa pero, como observaremos en el tercer epígrafe del artículo, durante los últimos años se han puesto en duda algunas de sus afirmaciones anteriores al llamarse la atención sobre el importante papel desempeñado por muchos hombres al servicio de la religión. La última parte del artículo se referirá al caso español, espacio historiográfico donde la investigación sobre el binomio género-religión en el siglo XIX ha sido hasta el momento más bien escasa así que se plantearán algunas propuestas futuras de investigación.

Como se podrá comprobar en las siguientes páginas, la cuestión de la feminización de la religión está estrechamente ligada con otros debates más generales como el de la secularización o el de la relación entre religión y modernidad. Si la feminización religiosa confirma o, por el contrario, cuestiona la tesis de la secularización o si la feminización puede considerarse uno de los mecanismos por los que la Iglesia trató de adaptarse a la modernidad liberal-burguesa son algunos de los dilemas sobre los que ha pivotado la discusión historiográfica en las últimas décadas. 5

5 Ante la casi inabarcable bibliografía sobre la teoría de la secularización y la relación entre la religión y la modernidad, me remito a las aportaciones realizadas en este mismo dossier y a algunos estados de la cuestión recientes escritos en castellano: Gregorio Alonso, «La secularización de las sociedades europeas», Historia Social, 46, 2003, pp. 137-157; Joseba Louzao, «La recomposición religiosa en la modernidad: un marco conceptual para comprender el enfrentamiento entre laicidad y confesionalidad en la España contemporánea», Hispania Sacra, LX, 121, 2008, pp. 331-354 y Francisco Javier Ramón y Raúl Mínguez, «Religión y modernidad», en José Antonio Caballero, Raúl Mínguez y Vega Rodríguez- Flores (eds.), Culturas políticas en la contemporaneidad. Discursos y prácticas políticas desde los márgenes a las élites, Asociación de Historia Contemporánea / Universitat de València, Valencia, 2015, pp. 7-13. 


\section{Los orígenes de la tesis de la feminización religiosa}

Para encontrar los comienzos de la tesis de la feminización de la religión hay que remontarse a Estados Unidos a mediados de los años setenta del siglo XX. En medio de la ola de feminismo iniciada, entre otras, por Betty Friedan con su Mística de la feminidad y en un momento en el que, ante la creciente presencia pública de algunos movimientos religiosos en todo el mundo, empezaba a cuestionarse la tesis de la secularización, prácticamente inmune desde que fuera planteada por Max Weber y Émile Durkheim a principios de siglo, un grupo de historiadoras comenzaron a analizar y a reivindicar el papel de las mujeres en las diferentes confesiones religiosas estadounidenses. Barbara Welter fue la primera autora en utilizar el concepto de feminización de la religión en un artículo publicado en 1973. ${ }^{6}$ Welter situaba los efectos de este proceso de feminización religiosa en el plano interno o simbólico y los conectó con la separación de esferas experimentada por la sociedad norteamericana tras la independencia:

«En el periodo inmediatamente posterior a la Revolución americana, las actividades políticas y económicas fueron consideradas más importantes y, por tanto, más "masculinas", es decir, requerían de mayor competitividad y agresividad y eran más susceptibles de requerir fuerza y solidez. La religión, junto con la familia y los gustos populares, no fue tan importante y se convirtió en un ámbito específico de las señoras. Así, la religión experimentó un proceso de cambio a través del cual se hizo más domesticada, más emocional, más indulgente y condescendiente, en una palabra, más "femenina"».7

Así pues, la religión adoptó una vertiente más amable y menos rigurosa que puede relacionarse, según la autora, con la interpretación de Dios como padre y madre a la vez y con la aparición de la figura de la Salvadora, un segundo mesías femenino que supuestamente llegaría a la Tierra para acabar con una era de vicio e incredulidad provocada por el fracaso de las leyes y valores masculinos. La Salvadora constituyó una interesante amalgama de la necesidad protestante de una alternativa al culto católico

${ }^{6}$ Yo he utilizado una recopilación posterior de la autora en la que aparece el mencionado artículo: Barbara Welter, «The feminization of American Religion, 1800-1860», en Dimity convictions. The American Woman in the Nineteenth Century, Ohio University Press, Athens (Ohio), 1985, pp. 83-102.

7 Barbara Welter, op. cit., 1985, p. 84. 
de la Virgen María y de la elevación de la feminidad pura a un nivel sobrenatural. Desde luego, la piedad, la pureza, la sumisión y la domesticidad, los cuatro elementos de la verdadera feminidad (true womanhood) exigida a las mujeres estadounidenses, estaban profundamente arraigados en valores religiosos y, de hecho, la Mujer Fuerte de la Biblia fue considerada uno de los principales ejemplos a seguir. ${ }^{8}$

Sin embargo, la religión permitió a las mujeres adoptar también un papel más activo en algunos ámbitos de la sociedad. Welter analizó más específicamente la participación femenina en las misiones realizadas en el Oeste y en el extranjero. Las primeras generaciones de misioneras estuvieron generalmente casadas y adoptaron un papel más bien subordinado respecto al desempeñado por sus maridos. Sin embargo, a causa de las costumbres locales y los tabúes de algunas comunidades, las mujeres paganas eran prácticamente inaccesibles para los misioneros varones por lo que se incrementó la demanda de misioneras femeninas a tiempo completo. Eso permitió que cada vez más mujeres solteras pudieran dedicarse a las misiones. Si en 1830 las mujeres misioneras ya representaban el 49\% de la fuerza misionera, en 1880 constituían el 57\% del total de misioneros activos, una cifra que subió a más del $60 \%$ en $1893 .{ }^{9}$

Según Welter, las misioneras, particularmente las solteras, consiguieron alcanzar un espacio de libertad además de promoción social y personal, una idea que desarrolló Nancy Cott para el caso de las mujeres de clase mediaalta de Nueva Inglaterra a principios del siglo XIX. ${ }^{10}$ Cott realizó una afirmación innovadora para la historiografía de la época: el feminismo creció a raíz y como reacción a la ideología de la domesticidad, no al contrario. En ese sentido, destacó la importancia de la religión en el proceso de constitución identitaria de muchas mujeres. La gran cantidad de asociaciones maternales y de reforma moral de la sociedad surgidas en esta época posibilitó el surgimiento de una especie de hermandad femenina que, con el paso del tiempo, acabó reivindicando derechos para las mujeres. La religión permitió a las mujeres confiar en una autoridad ajena al mundo de los hombres y les suministró un apoyo crucial cuando pretendieron ir más allá de los lími-

8 Barbara Welter: «The cult of True Womanhood: 1820-1860», American Quarterly, 18-2, 1966, pp. 151-174.

${ }^{9}$ Barbara Welter, «She hath done what she could: Protestant Women's Missionary Careers in Nineteenth-Century America», American Quarterly, 30-5, 1978, pp. 624-638.

10 Nancy F. Cott, The bonds of womanhood. «Woman's Sphere» in New England, 1780-1835, Yale University Press, New Haven and London, 1997 (1. a ed. 1977). 
tes establecidos. ${ }^{11}$ La fe religiosa aportó también a las mujeres una especie de egoísmo santo como resultado del auto-examen intrínseco a la tradición calvinista. En contraste con la abnegación requerida por las mujeres en su vocación doméstica, el compromiso religioso requería atención a los pensamientos, acciones y proyectos de uno mismo.

La feminización religiosa acabó también teniendo efectos en la propia cultura estadounidense. Según defendió Ann Douglas en una de sus obras más influyentes, la sociedad norteamericana de mediados de siglo XIX estuvo conformada por una masa creciente de consumidores culturales que potenciaron el cambio de una teología calvinista de fuerte contenido intelectual a una religiosidad mucho más piadosa que se expresó en novelas de carácter doméstico y fuertemente emocional: amores desafortunados, esposas sufrientes, maridos caprichosos y muertes de hijos pequeños. Los protagonistas de esta decisiva transformación cultural fueron los pastores liberales del noreste del país, las mujeres de clase media y algunos de los escritores masculinos más populares del momento. En opinión de Douglas, el resultado de este proceso de feminización fue la conformación de una cultura sentimental $\mathrm{y}$ anti-intelectual cuyos ecos permanecieron durante largo tiempo. ${ }^{12}$

Así pues, en esta primera fase anglosajona o estadounidense de la tesis de la feminización religiosa se definieron ya algunos de sus rasgos principales: la contribución de la religión en la conformación de los modelos de feminidad de la época, su relevancia en la construcción identitaria de numerosas mujeres y su influencia en el modelado de una cultura de carácter más popular y sentimental. Desde principios de los años ochenta se desarrollaron estos aspectos y se abrieron nuevas perspectivas pero el centro neurálgico de las investigaciones relacionadas con la tesis de la feminización religiosa se trasladó al continente europeo.

\section{La historia social y antropológica de la feminización de la religión}

Durante la década de los ochenta y parte de los noventa, la historiografía francesa adoptó la voz cantante en los estudios históricos sobre la

${ }^{11}$ Sue Morgan también ha insistido recientemente en esta idea: Sue Morgan, «Rethinking religion in gender history: historiographical and methodological reflections», en Ursula King y Tina Beattie (eds.), Gender, religion and diversity. Cross-Cultural Perspectives. Continuum, London / New York, 2005, pp. 113-124.

12 Ann Douglas: The Feminization of American Culture, Alfred A. Knopf Inc., Nueva York, 1977. 
feminización religiosa aunque no se pueden obviar las contribuciones de otras historiografías nacionales, especialmente la italiana. Si en la etapa anterior los principales estudios se habían realizado en el ámbito protestante, ahora se centrarán preferentemente en el mundo católico. La influencia de la denominada escuela de los Annales fue evidente por el fuerte carácter sociológico y antropológico que tuvieron muchos de los trabajos sobre la feminización religiosa. En concreto, tres fueron los principales temas de estudio desarrollados durante estos años: la práctica religiosa, la piedad y la composición interna del clero. ${ }^{13}$

\section{Cuadro I}

Series diocesanas de personas que tomaron la comunión en Pascua

\begin{tabular}{ccccc}
\hline Diócesis & Años & $\begin{array}{c}\text { Porcentaje de } \\
\text { hombres sobre el } \\
\text { total de hombres }\end{array}$ & $\begin{array}{c}\text { Porcentaje de } \\
\text { mujeres sobre el } \\
\text { total de mujeres }\end{array}$ & $\begin{array}{c}\text { Proporción de } \\
\text { hombres por } \\
\text { cada mujer }\end{array}$ \\
\hline \multirow{4}{*}{ Périgueux } & 1841 & 24 & 67 & 0,36 \\
& 1855 & 31 & 70 & 0,44 \\
& $1879-1886$ & 36 & 75 & 0,48 \\
& $1899-1906$ & 38 & 76 & 0,50 \\
Agen & $1842-1846$ & 33 & 69 & 0,55 \\
\hline \multirow{4}{*}{ Chartres } & 1876 & 36 & 67 & 0,49 \\
& 1890 & 36 & 71 & 0,51 \\
& 1914 & 13 & 68 & 0,53 \\
& 1868 & 4 & 37 & 0,35 \\
\hline \multirow{4}{*}{ Nevers } & 1874 & 4 & 40 & 0,11 \\
& 1898 & 2 & 15 & 0,09 \\
& $1844-1845$ & 18 & 15 & 0,10 \\
& 1886 & 19 & 57 & 0,10 \\
\hline
\end{tabular}

Fuente: Ralph Gibson, «Le catholicisme et les femmes en France au XIX ${ }^{\mathrm{e}}$ siècle», Revue d'Histoire de l'Église de France, 79, 202, 1993, pp. 63-93 (cuadro en p. 93).

13 Aunque la mayor parte de los trabajos que se van a citar y a comentar en este segundo epígrafe fueron publicados entre principios de los ochenta y mediados de los noventa, en aras de una mejor claridad expositiva se van a incorporar en este epígrafe otros estudios posteriores que, sin embargo, comparten con los primeros una perspectiva sociológica y/o antropológica. 
A través de indicadores susceptibles de ser analizados cuantitativamente como la asistencia dominical a misa o la toma de comunión en Pascua, historiadores y sociólogos franceses acuñaron el término de $d i$ morfismo sexual para referirse a las notables diferencias entre hombres y mujeres en lo que a la práctica religiosa se refiere. Al parecer, el proceso de descristianización que Michel Vovelle analizó para el siglo XVIII afectó más a hombres que a mujeres y, tras la Revolución francesa, la brecha se abrió todavía más. ${ }^{14}$ Así lo muestra el cuadro con datos recopilados por Ralph Gibson para distintas diócesis francesas (véase cuadro I). Como se puede observar, en todas las diócesis recogidas las mujeres tomaron la comunión en Pascua y asistieron a misa de manera más regular que los hombres. Aunque con variaciones regionales, este patrón se repite durante todo el periodo, circunstancia que llevó a Gibson a afirmar que el dimorfismo sexual se encontraba plenamente consolidado en Francia en el comienzo de la serie estadística, es decir, a mediados del siglo XIX y se mantuvo, como mínimo, hasta principios del siglo XX. ${ }^{15}$

La piedad y la devoción decimonónicas han sido también aspectos bastante abordados por la historiografía religiosa desde los años ochenta, en este caso con una marcada perspectiva antropológica. La conclusión general a la que se ha llegado es que, al igual que ocurrió en el mundo protestante, el catolicismo adoptó un carácter más sentimental y popular, en gran parte potenciado por el proceso de romanización eclesiástica y de exaltación de la figura del papa. Se trató, por tanto, de una piedad más intimista, en la que se buscaba el trato personal y frecuente con Dios mediante los devocionarios, el rezo del rosario o los ejercicios espirituales. El recurso a la divinidad en cuestiones relacionadas con la enfermedad, las catástrofes naturales o las revoluciones fue otro de los rasgos de esta piedad decimonónica que, aunque no era esencialmente nuevo dentro del imaginario católico, sí adoptó especial relevancia en un siglo supuestamente dominado por la ciencia y la razón. Además, la mayor tolerancia eclesiástica hacia la religiosidad popular se tradujo en un gusto mayor por las expresiones de pobreza, simplicidad y humildad. El culto a la Virgen María, especialmente desde su proclamación dogmática como Inmaculada

${ }^{14}$ Michel Vovelle, Piété baroque et déchristianisation en Provence au XVIIIe siècle. Les attitudes devant la mort d'après les clauses de testaments, Seuil, Paris, 1978.

15 Ralph Gibson., op. cit. (1993), pp. 63-93. 
Concepción en 1854, fue el que mejor representó la piedad católica durante el siglo XIX. ${ }^{16}$

Además del rosario, se extendieron durante el siglo XIX por toda la Europa católica otras devociones asociadas a la Virgen como la dedicación del mes de mayo a su figura o el Sagrado Corazón de María. ${ }^{17}$ Pero el fenómeno sin duda más llamativo y mejor estudiado fueron las apariciones marianas. El país donde la Iglesia reconoció oficialmente mayor número de apariciones, cuatro en total, fue precisamente Francia: París (1830), La Salette (1846), Lourdes (1858) y Pontmain (1871). ${ }^{18}$ Resulta llamativo que las beneficiarias de estas y otras muchas apariciones fueran mujeres jóvenes y niños cuando en otras épocas y contextos había existido una clara hegemonía masculina. ${ }^{19}$ Como señaló en su momento Marlène Albert, el hecho de que mujeres y niños, generalmente pobres y analfabetos, fueran los que con más frecuencia durante el siglo XIX vieran a la Virgen ha de explicarse por la propia feminización de la piedad católica. ${ }^{20}$

Los investigadores que se han acercado a esta cuestión también han enfatizado su carácter político y movilizador, que debe relacionarse con el nuevo clima institucional, político e ideológico instaurado por los regímenes liberales. Así, las apariciones marianas se inscribieron normalmente en un movimiento de contestación de fuerte carga emotiva y po-

16 Claude Langlois, «Le temps de l'immaculée conception. Définition dogmatique (1854) et événement structurant», en Bruno Béthouart y Alain Lotin (eds.), La dévotion mariale de l'an mil à nos jours, Artois Presse Université, Arras, 2005, pp. 365-379.

17 Marina Caffiero, Religione e modernità in Italia (secoli XVII-XIX), Istituti Editoriali e Poligrafici Internazionali, Pisa/Roma, 2000, pp. 181-189.

18 Algunos trabajos que han estudiado el fenómeno de las apariciones de la Virgen y sus repercusiones, preferentemente en la Francia decimonónica, son Joachim Bouflet y Philippe Boutry, Un signe dans le ciel. Les apparitions de la Vierge, Bernard Grasset, Paris, 1997; Yves-Marie Hilarie: «Évolution du culte marial au XIXe siècle en France», en Bruno Béthouart y Alain Lotin (eds.): op . cit. (2005), pp. 41-49; Thomas A. Kselman, Miracles and Prophecies in Nineteenth-Century France, Rutgers University Press, New Brunswick 1983; Sandra L. Zimdars-Swartz, Encountering Mary. From La Salette to Medjugorje. Princeton University Press, Princeton, 1991 y David Blackbourn, Marpingen: Apparitions of the Virgin Mary in Bismarckian Germany, Clarendon Press, Oxford, 1993.

19 Por ejemplo, entre 1399 y 1592 hubo en España tres veces más videntes masculinos que femeninos y además, de edades muy diversas. Véase William A. Christian, «Six Hundred Years of Visionaires in Spain: Those believed and Those ignored», en Michael Hanagan, Leslie Page Moch y Wayne Brake (eds.): Challenging Authority: The Historical Study of Contentious Politics. Minneapolis, University of Minnesota Press, 1998, pp. 107-119.

${ }_{20}$ Marlène Albert Llorca, «Les femmes dans les apparitions mariales de l'époque contemporaine», Clio, Histoire, Femmes et Sociétés, 15, 2002, pp. 123-134. 
pular, de carácter contrarrevolucionario y filopapista. Marina Caffiero ha documentado en Italia varios casos de profetisas, la mayoría procedentes de estratos humildes de la sociedad y que, desde finales del siglo XVIII, se manifestaron generalmente favorables al papa de Roma. ${ }^{21}$ Algo parecido ocurrió con Lourdes aunque es verdad que la aparición de la Virgen a Bernadette Soubirous en 1858 tuvo un efecto movilizador mucho más acusado. De hecho, en los años setenta, los realistas convocaron un peregrinaje nacional a esta pequeña población pirenaica con la intención de apoyar el proyecto de restablecer el poder temporal del papa en la Península italiana y de restaurar en Francia la alianza entre el trono y el altar. En los años noventa, el movimiento se hizo progresivamente antisemita ya que los organizadores de las peregrinaciones, que eran anti-Dreyfus, pretendían excluir socialmente a judíos, francmasones y republicanos. Así pues, el viaje a Lourdes fue, en opinión de Ruth Harris, «el acontecimiento por excelencia de una contracultura católica opuesta a las campañas anticlericales de la nueva República laica». ${ }^{22}$

El tercer aspecto sobre el que se centraron los historiadores interesados en la feminización de la religión fue el notable incremento de mujeres religiosas dentro del clero. El siglo XIX asistió a la emergencia de las congregaciones femeninas de vida activa, una forma de vida religiosa que no era novedosa dentro del catolicismo pero que experimentó un desarrollo notable durante el ochocientos por su capacidad de adaptación a la cambiante situación social y por acabar convenciendo, no sin resistencias, a la jerarquía eclesiástica. A diferencia de las más tradicionales monjas de clausura, las congregacionistas se caracterizaban por no emitir en primera instancia votos solemnes, por tener una existencia activa y móvil, por desarrollar una actividad fundamentalmente social (trabajaban preferentemente en escuelas y hospitales), por estar teóricamente bajo jurisdicción episcopal (las órdenes religiosas estaban controladas por el clero regular) y, sobre todo, por estar sus comunidades dirigidas por una

${ }^{21}$ Sin embargo, no siempre fue así ya que Caffiero recoge también el caso de Suzette Labrousse, una profetisa laica que en 1792 trató de convencer al papa Pío VI de que debía apoyar la Revolución francesa, renunciar al poder temporal y mantener sólo el poder espiritual de la Iglesia. Marina Caffiero, «Donne religione e modernità in Italia. La femminilizzazione religiosa tra nuove congregazioni e nuove profezie (XVIII-XIX secolo)», en Ana Yetano (coord.), Mujeres y culturas políticas en España, 1808-1845, Universidad Autónoma de Barcelona, Barcelona, 2013, pp. 25-38

22 Ruth Harris, Lourdes. La grande histoire des apparitions, des pèlerinages et des guérisons, JC Lattès, Paris, 2001 p. 29. 
superiora general y una casa madre a diferencia de las comunidades de clausura, que eran autónomas y cada una tenía sus propias reglas de vida en común.

Con una metodología generalmente cuantitativa, historiadores franceses e italianos como Claude Langlois, Yvonne Turin, Gérard Cholvi, Giancarlo Rocca o la ya mencionada Marina Caffiero han aportado información muy interesante para comprender aspectos clave relacionados con el fenómeno congregacionista femenino como sus orígenes en el siglo XVIII, su rápido crecimiento en la centuria siguiente, la interesante figura de la superiora general, la extracción social de las religiosas y sus motivos para acceder a una congregación. ${ }^{23}$ Como podemos observar en los cuadros II y III referidos a Francia e Italia respectivamente, el auge del movimiento congregacionista fue bastante más temprano en el caso francés ya que comenzó prácticamente en tiempos de la Revolución. Hasta 1880, el ritmo de fundación de congregaciones femeninas francesas fue bastante sostenido gracias, entre otras cosas, a un poder político que no sólo no dificultó sino que, en algunas ocasiones, llegó a favorecer este proceso, como ocurrió durante la primera década del Segundo Imperio. Precisamente, fueron también circunstancias políticas las que provocaron que, a partir de 1880, el movimiento congregacionista languideciera rápidamente, en este caso debido a la laicización de la enseñanza por parte de gobiernos de la Tercera República. En Italia, la aceleración del proceso fundacional fue más tardía que en Francia ya que se produjo a partir de la unificación pero se prolongó prácticamente hasta mediados del siglo siguiente favorecido por el régimen fascista de Mussolini. El fenómeno congregacionista femenino también se desarrolló en estados donde los católicos no representaban la confesión mayoritaria, como Prusia. Bernhard Schneider señala que entre 1850 y 1880 se fundó la nada despreciable cifra de 22 congregaciones femeninas mientras que

${ }^{23}$ Claude Langlois, Le catholicisme au féminin. Les congrégations françaises à supérieure générale au XIXe siècle, Cerf, Paris, 1984; Claude Langlois, «Le catholicisme au féminin revisité» en Alain Corbin, Jacqueline Lalouette y Michèle Riot-Sarcey (dirs.): Femmes dans la Cité (1815-1871), Créaphis, Grânc, 1997, pp. 139-149; Yvonne Turin, Femmes et religieuses au XIXe siècle. Le féminisme «en religion». Nouvelle Cité, Paris, 1989; Gérard Cholvi, Le XIXe. Grand siècle des religieuses françaises. Artège, Perpignan, 2012; Giancarlo Rocca, Donne religiose. Contributo a una storia della condizione femminile in Italia nei secoli XIX e XX. Paoline, Roma, 1992 y Marina Caffiero, op cit. (2013), pp. 25-38. 
en 1907, el 64\% del clero católico presente en el principal estado de Alemania estaba conformado por monjas o congregacionistas. ${ }^{24}$

\section{Cuadro II}

Fundación de congregaciones femeninas en Francia (1800-1880)*

\begin{tabular}{rcc}
\hline Años & Número de fundaciones & Media anual \\
\hline $1800-1809$ & 38 & 3,8 \\
$1810-1819$ & 33 & 3,3 \\
$1820-1829$ & 46 & 4,6 \\
$1830-1839$ & 49 & 4,9 \\
$1840-1849$ & 49 & 4,9 \\
$1850-1859$ & 50 & 5 \\
$1860-1869$ & 39 & 3,9 \\
$1870-1879$ & 22 & 2,2 \\
\hline
\end{tabular}

Fuente: Langlois, op. cit. (1984), pp. 223-224.

* Sólo aparecen las congregaciones en las que Langlois ha conseguido desvelar su lugar de fundación.

\section{Cuadro III}

Fundación de congregaciones femeninas en Italia (1801-1973)

\begin{tabular}{rcc}
\hline Años & Número de fundaciones & Media anual \\
\hline $1801-1866$ & 79 & 1,19 \\
$1867-1899$ & 106 & 3,21 \\
$1900-1914$ & 31 & 2,06 \\
$1915-1949$ & 110 & 3,14 \\
$1950-1973$ & 21 & 0,87 \\
\hline
\end{tabular}

Fuente: Rocca, op.cit. (1992), p. 47.

${ }^{24}$ Bernhard Schneider, «The Catholic poor relief discourse and the feminization of the caritas in early nineteenth century Germany», en Patrick Pasture, Jan Art y Thomas Buerman (eds.), Beyond the feminization thesis. Gender and Christianity in Modern Europe, Leuven University Press, Leuven, 2012, pp. 35-55 (datos referidos en pp. 51-53) 
Dentro del mundo protestante, concretamente en los países luteranos, es digno de destacar el movimiento de las diaconisas, que en algunos aspectos se asemejó bastante a las congregaciones católicas. Las diaconisas fueron, por lo general, mujeres jóvenes con fuertes inquietudes religiosas que se dedicaron preferentemente a la enseñanza primaria, el cuidado sanitario y la atención a los pobres. Llevaron un uniforme identificativo, emitían un voto de obediencia a sus superiores y debían permanecer célibes mientras fueran diaconisas, un aspecto que generó cierta tensión en el seno de las Iglesias luteranas. Sin embargo, a diferencia de las congregaciones católicas, las diaconisas no disfrutaron del liderazgo formal de su organización ya que este recayó generalmente en personal laico o en sacerdotes luteranos. Además, desde el punto de vista cuantitativo el movimiento diaconal femenino no logró las espectaculares cifras alcanzadas por las congregaciones femeninas. De hecho, setenta y cinco años después de la fundación de la primera casa madre, había en 1910 un total de casi 15.000 diaconisas contando todos los países luteranos, una cifra claramente inferior a las 130.000 congregacionistas que existían sólo en Francia en 1878. ${ }^{25}$

Sin duda, los estudios mencionados contribuyeron a consolidar la tesis de la feminización religiosa al analizar con exhaustividad muchos de los fenómenos y efectos asociados a ella. Se llegó así a la conclusión de que el cristianismo decimonónico había atraído a más mujeres que a hombres pero no se explicaron las causas con claridad ni tampoco se introdujo, salvo en algunos trabajos concretos, el debate sobre si esta feminización religiosa podía considerarse, utilizando un juego de palabras, una simple reacción antimoderna o una respuesta moderna a la modernidad.

\section{El giro discursivo de la feminización de la religión y la emergencia de la masculinidad}

Durante los años noventa, la teoría de la feminización de la religión tal como fue desarrollada por la historia social en los años anteriores comenzó a mostrar claros síntomas de agotamiento. Algunas de sus hipótesis más asentadas empezaron a ser fuertemente cuestionadas. James McMillan, historiador escocés especializado en la Francia contemporánea, fue uno de

${ }_{25}$ Un buen estudio sobre el movimiento de las diaconisas en Suecia, crítico con la teoría clásica de la secularización, es el siguiente: Todd H. Green, Responding to secularization. The Deaconess Movement in Nineteenth-Century Sweden. Brill, Leiden / Boston, 2011. 
los primeros en criticar varios postulados de la tesis de la feminización religiosa. En un trabajo publicado en 1991, este autor no sólo llamaba la atención sobre la necesidad de no olvidar a hombres que habían sido profundamente religiosos - tema que abordaré después - sino que también ponía en duda la supuesta mayor religiosidad de las mujeres. ${ }^{26}$ Así, consideraba que los motivos estrictamente religiosos no eran los únicos que estaban detrás de las miles de mujeres que durante el siglo XIX decidieron incorporarse a un instituto religioso. Existieron otros factores más mundanos como la ambición por poder hacer una carrera profesional o la voluntad de huir de una vida matrimonial no siempre satisfactoria. De la misma manera, numerosas mujeres laicas no sólo se involucraron en las actividades religiosas por la espiritualidad sino también por la sociabilidad que aportaban ya que, a diferencia de los hombres, las mujeres tenían pocos espacios en donde poder reunirse y la parroquia fue precisamente uno de ellos. Por otra parte, McMillan también cuestionaba la presencia de una piedad ultramontana plenamente feminizada porque, como se encargaba bien de recordar, esta había sido impulsada especialmente por un varón, el papa Pío IX, por motivos políticos: la legitimación de su autoridad ante el naciente estado italiano y frente a las simpatías liberales presentes en el seno del catolicismo.

Otro aspecto bastante conflictivo fue el de la práctica religiosa. No se cuestionó que durante el siglo XIX fueran las mujeres quienes asistieran con más asiduidad a los oficios religiosos sino el hecho de que esto supusiera realmente una novedad. Algunos autores han remontado esta preponderancia incluso a la Edad Media ${ }^{27}$ pero, sin duda, uno de los trabajos globalmente más críticos con la tesis de la feminización fue el publicado por Ann Braude en 1997.28 Esta historiadora norteamericana afirmaba con rotundidad que, ya desde mediados del siglo XVII, las mujeres habían sido mayoritarias en todas las confesiones religiosas estadounidenses, tanto del norte como del sur y tanto blancas como negras. En su opinión, lo que

26 James McMillan, «Religion and gender in modern France: some reflections» en Frank Tallet y Nicholas Atkin (eds.), Religion, Society and Politics in France since 1789, Hambledon Press, Ohio, 1991, pp. 55-66.

27 Jacques Dalarun, «Dieu changea de sexe, pour ainsi dire». La religion faite femme $X I^{e}-X V^{e}$ siècle, Fayard, Paris, 2008.

28 Ann Braude, «Women's History is American Religious History», en Thomas A. Tweed (ed.), Retelling US Religious History, University of California Press, Berkeley, 1997, pp. 87-107. Otra obra de la misma autora, escrita para una audiencia más general, es la siguiente: Ann Braude, Sisters and Saints: Women and American Religion, Oxford University Press, New York, 2007. 
existió durante el siglo XIX fue, como mucho, un incremento en la ya mayoritaria proporción de mujeres que asistían regularmente a misa respecto a los varones. Así pues, el término feminización reflejaba en realidad las preocupaciones y ansiedades de los clérigos protestantes de la época ante la disminución de la presencia masculina en las iglesias, una percepción que se remonta precisamente al periodo de formación de las primeras colonias británicas en Norteamérica pero que, según Braude, ha sido heredada de forma acrítica por muchos historiadores recientes.

En sus orígenes, la tesis de la feminización religiosa había surgido como respuesta a la teoría clásica de la secularización por el hecho de plantear que la religión no había desaparecido en la modernidad sino que había resistido gracias, en buena medida, a las mujeres. Sin embargo, la reflexión de Braude hizo invertir el planteamiento: al percibirse la feminización religiosa en términos de declive y de nostalgia por un mundo dominado por varones profundamente religiosos que en realidad nunca existió (al menos en EE.UU.), la tesis de la feminización no hacía más que confirmar la teoría de la secularización. Así pues, la religión había quedado recluida durante la modernidad en la esfera privada y femenina, considerada de menor importancia al compararla con la esfera pública, secular y masculina.

Al hablar de percepciones más que de realidades y en un contexto en el que la historiografía se encontraba en pleno proceso de discusión y debate ante el denominado giro lingüístico, trabajos como el de Braude abrieron la veda para que se conformara a partir del cambio de siglo una historia discursiva de la feminización religiosa. A diferencia de la historia social, que se había centrado en describir con una metodología preferentemente cuantitativa los elementos y efectos reales de la feminización religiosa, la historia discursiva se ha especializado más bien en el análisis de las categorías a partir de los cuales los individuos dotaron de significado a la realidad. En un artículo relativamente reciente, Inmaculada Blasco explicaba en estos términos la manera en que se podía desarrollar una historia discursiva de la feminización religiosa:

«¿No sería más adecuado hablar de feminización de la religión como una parte más de la organización del conocimiento de la diferencia sexual en unas sociedades que estaban transformando su concepción de la religión? En otras palabras, habría que partir de una comprensión tanto de la feminización de la religión como de la diferencia sexual en tanto que organizadores de conocimiento o categorías a través de las cuales los contemporáneos percibieron y dieron sentido a sí mismos y a su entorno. Entendidos así, la conexión concreta entre ambos fenóme- 
nos consistiría en que la diferencia sexual que se configuró a lo largo del siglo XIX generó una serie de atribuciones de feminidad y masculinidad, entre las cuales destacaría el tipo de relación mantenida con la religión y la espiritualidad. A medida que la indiferencia religiosa y el alejamiento de la Iglesia se convertían en atributo naturalizado de masculinidad, una mayor religiosidad iba constituyendo la feminidad decimonónica». ${ }^{29}$

Como se puede observar, la propuesta de Blasco insistía en la necesidad de analizar la forma en que los discursos disponibles en un determinado contexto histórico contribuyeron a la construcción cultural de la diferencia sexual. Este enfoque discursivo no busca comprender la feminización de la religión como una realidad objetiva y cuantificable sino «como elemento constitutivo del imaginario social moderno en torno a la diferencia sexual y a la religión». ${ }^{30}$ En ese sentido, la vinculación aparentemente natural entre mujeres y religión durante el siglo XIX fue realmente una construcción discursiva, una categoría o lente a partir de los cual los coetáneos percibieron la realidad y la dotaron de significado.

En la última década, la mayoría de los estudios internacionales sobre la relación entre género y religión en la contemporaneidad han seguido esta perspectiva discursiva. En concreto, voy a referirme aquí a dos grupos de investigación europeos: el primero se ha centrado en la historia sociorreligiosa de Bélgica entre 1750 y 1950 y su objetivo ha sido ir más allá de la tesis de la feminización religiosa mientras que el segundo ha estudiado la masculinidad cristiana en los países del norte de Europa entre 1840 y $1940 .{ }^{31}$ Ambos proyectos han relativizado y contextualizado histó-

${ }^{29}$ Inmaculada Blasco, «Género y religión: de la feminización de la religión a la movilización católica femenina. Una revisión crítica», Historia Social, 53, 2005, pp. 119-136 (cita en p. 123).

30 Ibid, p. 127.

${ }^{31}$ Los títulos completos de estos proyectos son, respectivamente, In search of the good Catholic m/f. Feminization and masculinity in Belgian Catholicism (c. 1750-1950) y Christian manliness - a paradox of modernity: Men and Religion in a Northern European Context (1840-1940). Las principales publicaciones que se han derivado de ellos y que a continuación analizaré son los siguientes: Patrick Pasture, Jan Art, Thomas Buerman (eds.), Beyond the feminization thesis. Gender and Christianity in Modern Europe, Leuven University Press, Leuven, 2012; Tine Van Osselaer, The pious sex. Catholic Constructions of Masculinity and Femininity in Belgium, c. 1800-1940, Leuven University Press, Leuven 2013; Tine Van Osselaer, Patrick Pasture (eds), Christian Homes: Religion, Family and Domesticity in the 19th and 20th Centuries, Leuven University Press, Leuven, 2014 y 
ricamente el concepto de feminización religiosa, han prestado gran atención a la construcción de la masculinidad por parte tanto del catolicismo como del protestantismo y han analizado las motivaciones políticas que estuvieron detrás de la inclusión de la categoría de género en el discurso público de ambas religiones.

Un aspecto en el que parece existir consenso entre las historiadoras e historiadores que se han movido dentro de esta línea interpretativa es que el proceso de feminización no se desarrolló en todas las esferas de la religión..$^{32}$ Formas específicas de devoción, los ritos y la religiosidad doméstica fueron los ámbitos que adquirieron un mayor grado de feminización seguidos de cerca por todas las actividades relacionadas con la educación y la caridad, que estuvieron en su mayor parte bajo control de las diaconisas y de las congregaciones femeninas (aunque también existieron congregaciones de vida activa formadas por varones, fueron bastante menos numerosas). ${ }^{33}$ En cambio, la hegemonía masculina no sólo fue evidente en relación al mantenimiento del poder patriarcal del clero sino que además, todas las áreas relacionadas con la movilización social y política en defensa del cristianismo (asociaciones de laicos, prensa y partidos políticos) contaron con una amplia mayoría masculina. ${ }^{34}$

A pesar de este intento de relativizar el alcance de la feminización religiosa, la mayoría de estos autores reconocen que, especialmente en el caso del catolicismo, sí existió una clara vinculación discursiva de las mujeres con la religión durante gran parte del siglo XIX. Sólo así se puede entender que el proceso de remasculinización iniciado a finales de esta centuria en el seno de diferentes confesiones cristianas tuviera como principal

Yvonne Maria Werner (ed.), Christian Masculinity. Men and Religion in Northern Europe in the $19^{\text {th }}$ and $20^{\text {th }}$ Centuries. Leuven University Press, Leuven, 2011.

32 Así se enfatiza especialmente en Bernhard Schneider, op . cit. (2012), pp. 35-55 (en particular pp. 36-37) y en Bernhard Schneider, op. cit. (2002), pp. 123-147.

33 Olaf Blaschke, al analizar los datos disponibles sobre toma de la comunión en algunas parroquias luteranas de Alemania durante el siglo XIX y principios del siglo XX, relativiza incluso esta superioridad femenina en la práctica religiosa porque señala que nunca superó el $60 \%$ del total, una ligera mayoría que en su opinión puede ser simplemente explicada por la mayor esperanza de vida de las mujeres. Olaf Blaschke, «The unrecognised piety of men. Strategies and success of the re-masculinisation campaign around 1900», en Yvonne Maria Werner (ed.), op. cit. (2011), pp. 21-45 (datos en pp. 25-29).

${ }^{34}$ Un trabajo interesante realizado sobre más de 800 miembros varones de la Sociedad de San Vicente de Paúl, fundada por Frédéric Ozanam a mediados del siglo XIX, es Matthieu Brejon de Lavergnée, «Making the charitable man. Catholic masculinities in nineteenth-century France», en Tine Van Osselaer, Patrick Pasture (eds.), op. cit. (2014), pp. 82-103. 
objetivo demostrar que los hombres podían ser verdaderos hombres sin renunciar a sus creencias cristianas. Así, prácticas discursivamente feminizadas como la asistencia a misa o la toma de la comunión se consideraron a partir de entonces como deberes del buen cristiano, que luchaba por los derechos de Cristo y que reforzaba su masculinidad al resistir con tenacidad lo que otros hombres pudiesen pensar de él. ${ }^{35}$ Un modelo de masculinidad que adquirió especial relevancia en este contexto fue el cristiano musculoso, un hombre fuerte y atlético pero que reservaba la fuerza de sus puños a defender a los más débiles, en concreto a niños y mujeres. De esta manera, el cristiano musculoso no sólo debía ser físicamente fuerte sino también desde el punto de vista moral y religioso. ${ }^{36}$

Aunque los esfuerzos realizados fueron notables, los protestantes y especialmente los católicos tuvieron bastantes dificultades a la hora de compatibilizar su modelo de masculinidad con una religión acusada por sus contrincantes políticos de haberse afeminado. Por ejemplo, en el agitado contexto de la Kulturkampf alemana, se puede afirmar que existió una auténtica guerra de género porque los políticos liberales no sólo percibieron a la Iglesia católica romana como femenina y al Estado como masculino sino que también reaccionaron con temor ante la presencia y participación de las mujeres católicas en la esfera pública. ${ }^{37}$ Pero estos intentos de presentarse como genuino representante de los valores masculinos al mismo tiempo que se feminizaba al enemigo para desprestigiarlo ante la opinión pública también se produjeron entre corrientes de una misma confesión religiosa, como ocurrió en el seno del propio catolicismo alemán entre finales del siglo XIX y principios del siglo XX. ${ }^{38}$

35 Olaf Blaschke op. cit., pp. 34-36, Yvonne Maria Werner, «Alternative masculinity? Catholic missionaries in Scandinavia» y Nanna Damsholt, «Danish folk high school and the creation of a new Danish man», en Yvonne Maria Werner (ed.), op. cit. (2011), pp. $165-187$ y $213-231$.

${ }^{36}$ Hugh McLeod, «The "Sportsman" and the "Muscular Christian". Rival ideals in nineteenth-century England», en Patrick Pasture et al. (eds), op. cit. (2012), pp. 85-105.

${ }^{37}$ Michael B. Gross, The war against Catholicism: Liberalism and the Anti-Catholic Imagination in Nineteenth-Century Germany. University of Michigan Press, Ann Arbor, 2004, especialmente pp. 185-238.

${ }^{38}$ Estos trabajos analizan perfectamente cómo se generizó el discurso de distintas corrientes dentro del catolicismo en su discusión en torno al celibato durante el II Reich: Angela Berlis, «Celibate or married priests? Polemical gender discourse in nineteenth-century Catholicism», en Patrick Pasture et al. (eds), op. cit. (2012), pp. 57-71 y Derek K. Hastings, «Fears of Feminized Church: Catholicism, Clerical Celibacy, and the Crisis of Masculinity in Wihelmine Germany», European History Quarterly, 38-1, 2008, pp. 34-65. 
La obra ya citada anteriormente de Tine Van Osselaer, fruto de su tesis doctoral, constituye un excelente ejemplo de esta renovadora manera de abordar la cuestión de la feminización religiosa que aglutina género, discurso y religión. En The Pious Sex, Van Osselaer se centra en Bélgica, un caso relativamente poco estudiado en cuanto a la relación entre género y religión se refiere. La cronología abarcada (desde principios del siglo XIX hasta la Segunda Guerra Mundial) es lo suficientemente amplia como para que la historiadora pueda analizar evoluciones y trayectorias de larga duración. A pesar de que las relaciones entre Iglesia y Estado en Bélgica, marcadas desde su independencia en 1830 por la libertad religiosa y la separación entre ambas instancias, fueron muy diferentes a la de los principales países católicos del sur de Europa; su estudio resulta muy pertinente por la oportunidad que ofrece de realizar análisis comparados y de valorar hasta qué punto el catolicismo fue también capaz de desenvolverse con soltura en situaciones donde no podía contar con el apoyo del Estado.

El libro se divide en tres partes bien diferenciadas. En la primera, sin duda la de mayor carga discursiva, Van Osselaer analiza de forma crítica la consideración de las mujeres como el sexo piadoso en el siglo XIX. ${ }^{39}$ Aunque reconoce la existencia de una_apelación positiva y laudatoria a la figura de la esposa y madre católica en el discurso público del catolicismo belga, el análisis de otros textos menos difundidos como los dirigidos específicamente a los sacerdotes muestran una visión menos amable de las mujeres, a las que se seguía considerando una amenaza potencial a la moralidad y pureza del clero. Además, como hizo Ann Braude para el caso estadounidense, Van Osselaer también cuestiona que la feminización de la práctica religiosa comenzara en el siglo XIX. En su opinión, el clero sólo comenzó a percibir como problemática la presencia mayoritaria de mujeres sobre hombres en las parroquias en un contexto, finales del siglo XIX, en el que fue consciente de que estaba perdiendo a una parte muy importante del laicado y que era necesario recuperar especialmente a la población masculina por la posición preeminente que ocupaba en la sociedad y en la familia.

Las dos últimas partes de la obra estudian de forma combinada discurso y acción católica desde una perspectiva de género. ${ }^{40}$ Concretamente, la segunda parte del libro se dedica a la devoción del Sagrado Co-

\footnotetext{
39 Tine Van Osselaer, op. cit. (2013), pp. 34-95.

40 Ibid., pp. 96-169 y 170-221.
} 
razón de Jesús en Bélgica. Lo que comenzó siendo a mediados del siglo XIX una devoción claramente feminizada con la presencia de una organización, el Apostolado de la Oración, formada mayoritariamente por mujeres, fue transformándose desde el cambio de siglo en una devoción cada vez más masculinizada. Las Ligas masculinas del Sagrado Corazón alcanzaron así una posición preeminente coincidiendo con la remasculinización del discurso católico. ${ }^{41}$ La tercera parte se centra en el análisis de las ramas masculinas y femeninas de la Acción Católica, tanto en el lado valón como en el flamenco, entre 1936 y 1940. La autora enfatiza especialmente la diferenciación discursiva respecto a las funciones a realizar dentro del movimiento: mientras que a los hombres se les atribuían virtudes como la fuerza, la voluntad, la independencia y la razón, que les convertían en mejores propagandistas, a las segundas se les atribuían otras cualidades como la dedicación, la servidumbre, el sentimiento y la ternura, que les permitía tener gran influencia en la familia.

Van Osselaer avisa de que los conceptos de feminización y masculinización aplicados a la religión tienen el peligro de mostrar una evolución lineal y simplista que no se corresponde con la realidad histórica. ${ }^{42}$ Para no caer en esa visión permanente y esencialista de lo masculino y lo femenino, es necesario tener en cuenta las zonas grises, aquellos espacios discursivos en los que lo masculino y lo femenino estuvieron entrelazados. Por ejemplo, no se percibió incompatible dentro del catolicismo hegemónico la expresión de emociones por parte de los hombres mientras que, en algunas ocasiones, se utilizó un vocabulario militarizado para describir las actividades de las mujeres católicas. Algunas investigaciones también han demostrado la impronta que dejaron las madres en el compromiso religioso de varones católicos. ${ }^{43}$ Así pues, los modelos católicos y protestantes de masculinidad y feminidad no fueron homogéneos sino que evolucionaron con el tiempo y se adaptaron a las circunstancias históricas de cada momento.

41 Sobre este tema, la autora también ha publicado el siguiente trabajo: Tine Van Osselaer, "“From that moment on, I was a man!" Images of the Catholic Male in the Sacred Heart Devotion», en Patrick Pasture et al. (eds), op. cit. (2012), pp. 121-135.

42 Tine Van Osselaer, op. cit. (2013), pp. 222-243.

43 Geneviève Gabbois: «"Vous êtes presque la seule consolation de l'Église". La foi des femmes face à la déchristianisation de 1789 à 1880», en Jean Delumeau (dir), La religion de ma mère. Les femmes et la transmission de la foi, Cerf, Paris, 1992, pp. 301-325 y Paul Seeley: «O Sainte Mère: Liberalism and the Socialization of Catholic Men in Nineteenth-Century France», The Journal of Modern History, 70-4, 1998, pp. 862-891. 
Por otra parte, la introducción de los hombres y de la masculinidad en el estudio de las religiones, aspecto prácticamente olvidado por las teorías de la secularización y de la feminización religiosa hasta finales del siglo pasado, ha obligado a replantear el debate entre religión y modernidad ya que ni los hombres fueron tan racionales y anticlericales ni la religión tan feminizada y privatizada como se creía. Desde luego, lejos de lo anunciado por los teóricos de la secularización, la religión no se ha convertido con la emergencia de la modernidad en un asunto exclusivamente privado y doméstico sino que ha continuado teniendo presencia en la esfera pública y afectando la vida de tanto hombres como mujeres.

\section{España: estado de la cuestión y propuestas de investigación}

Los estudios que han vinculado género y religión referidos a la España contemporánea han sido escasos si los comparamos con los que se han realizado para otras épocas históricas. Este déficit puede explicarse por un triple desinterés. En primer lugar, desinterés por parte de la historia académica o universitaria, empachada quizás por cuarenta años de nacionalcatolicismo y que sólo recientemente ha empezado a conformar grupos de investigación potentes sobre temas religiosos. Sin embargo, todavía se echa en falta una mayor presencia de la categoría de género en los trabajos publicados por estos grupos. Desgraciadamente, esta carencia no ha sido totalmente compensada por la historia de las mujeres, que durante bastante tiempo se ha preocupado especialmente por recuperar las acciones femeninas que condujeron a su emancipación. Al considerar a la Iglesia católica como una institución hostil a las mujeres, especialmente en la edad contemporánea, han sido escasos los trabajos que han relacionado catolicismo y mujeres. ${ }^{44}$ Finalmente, la historia eclesiástica, en concreto la realizada por algunas religiosas sobre la congregación a la que pertenecen, sí ha aportado algunos datos interesantes en relación a la evolución del fenómeno congregacionista en la España contemporánea. No obstante, estos trabajos dejan mucho que desear desde el punto de vista metodológico debido a una tendencia hagiográfica que en demasiadas ocasiones domina la interpretación histórica.

${ }^{44}$ Así se constata también en Inmaculada Blasco, «Sobre historia, religión y género. Algunas reflexiones en torno a las mujeres y el catolicismo en los albores del siglo XX», en Dolores Serrano-Niza y Beatriz Hernández (eds.), Mujeres y religiones. Tensiones y equilibrios de una relación histórica. Idea, Santa Cruz de Tenerife, 2008, pp. 319-341. 
Este panorama sombrío ha comenzado a aclararse en los últimos años gracias a la creciente publicación de trabajos que, con una metodología rigurosa y en un intento por dialogar con el debate internacional que he abordado en páginas anteriores, buscan integrar las categorías de género y religión en el análisis histórico. Este último epígrafe del artículo se plantea como objetivos reflexionar sobre los resultados obtenidos por estos trabajos y plantear posibles propuestas de investigación para el futuro.

Un primer aspecto a tener en cuenta es la propia naturaleza de la confesión religiosa dominante en España: el catolicismo. Nerea Aresti ya planteó hace unos años la necesidad de no perder de vista las diferencias que existieron entre catolicismo y protestantismo en cuanto a sus respectivos discursos de género se refiere. ${ }^{45}$ Desde luego, es evidente que el énfasis puesto por Lutero en la vida conyugal frente al celibato o el rechazo a la figura de la Virgen María con toda su carga simbólica marcaron claras diferencias con los modelos de masculinidad y feminidad propugnados por el catolicismo desde Trento. ${ }^{46}$ Pero lo realmente importante para el tema que nos ocupa es conocer mejor cómo se desplegaron los discursos de género protestantes y católicos en el agitado contexto del siglo XIX. Además, tampoco puede obviarse otro factor que, en mi opinión, puede ser igual o más decisivo incluso que la propia naturaleza de la confesión religiosa. Me estoy refiriendo a la posición ocupada por cada religión en el complejo juego de poderes decimonónico. Desde luego, no fue lo mismo disfrutar de una posición relativamente privilegiada como religión de Estado que competir con otras confesiones en un contexto de libertad religiosa. En función de la posición ocupada por cada religión en cada país, se puede explicar también las distintas y cambiantes relaciones de todas ellas con el liberalismo y de esa manera complejizar la asociación que tradicionalmente se ha hecho entre protestantismo-liberalismo-modernidad y catolicismo-antiliberalismo-tradición.

A pesar de los fuertes embates sufridos por la Iglesia católica durante la revolución liberal, el catolicismo español mantuvo durante gran

45 Nerea Aresti, «El ángel del hogar y sus demonios. Ciencia, religión y género en la España del siglo XIX», Historia Contemporánea, 21, 2000, pp. 363-394.

${ }^{46}$ En un interesante artículo, Luisa Accati analizó, desde una perspectiva antropológica, las consecuencias actuales de la cesura provocada en el siglo XVI por Lutero y el Concilio de Trento: Luisa Accati, «En busca de las diversidades perdidas. Conceptos anglosajones y madres mediterráneas», Duoda, 2, 1991, pp. 15-44 
parte del siglo XIX una posición privilegiada como religión oficial y apenas contó con competencia de otras confesiones religiosas. El mayor enemigo en el mantenimiento de sus privilegios fue, por tanto, el liberalismo, especialmente el ala progresista y demócrata de carácter anticlerical. Así pues, el discurso del catolicismo, también en lo que a cuestiones de género se refiere, se construyó muchas veces en contraposición del liberal si bien las analogías y continuidades entre distintas subcorrientes liberales y católicas fueron también muy importantes. La historiografía y la crítica literaria se han ocupado especialmente de analizar el ideal de domesticidad liberal-burgués ${ }^{47}$ mientras que los escasos estudios que se han centrado en el modelo de feminidad católico han aportado dos principales conclusiones: la existencia de notables continuidades pero también de importantes cambios respecto al modelo de feminidad contrarreformista y la presencia de variantes dentro del discurso católico de género, algunas de las cuales compartieron destacados aspectos con el ángel del hogar liberal burgués como la convicción de que la maternidad era el principal destino de la mujer. ${ }^{48}$ Desgraciadamente, apenas

47 Algunos de los trabajos más destacados son Bridget Aldaraca, El ángel del hogar: Galdós y la ideología de la domesticidad en España, Visor, Madrid, 1992; Catherine Jagoe, Alda Blanco y Cristina Enríquez de Salamanca, La mujer en los discursos de género. Textos y contextos en el siglo XIX, Icaria Barcelona, 1998; Alda Blanco, Escritoras virtuosas: narradoras de la domesticidad en la España isabelina, Universidad de Granada, Granada, 2001; Nerea Aresti, op. cit. (2001), pp. 363-394; Colette Rabaté, ¿Eva o María? Ser mujer en la época isabelina (1833-1868). Salamanca, Universidad de Salamanca, 2007; María Cruz Romeo, «Liberalismo e historia de las mujeres: ¿Una esfera pública definida y homogénea?» en Aurelia Martín y Manuel Martín (eds.), Mariana Pineda. Nuevas claves interpretativas, Comares, Granada, 2008, pp. 73-93; Isabel Molina, «La doble cara del discurso doméstico en la España liberal: El Angel del Hogar de Pilar Sinués», Pasado y Memoria, 8, 2009, pp. 181-198 y Mónica Burguera, Las damas del liberalismo respetable, Cátedra, Madrid, 2012.

48 Concretamente, para mediados del siglo XIX se podría hablar de una variante propiamente eclesiástica (el discurso sostenido por sacerdotes y obispos), otra neocatólica y otra carlista. Véase Raúl Mínguez, «Monjas, esposas y madres católicas: una panorámica de la feminización de la religión en España a mediados del siglo XIX», Amnis, 11, 2012, edición digital: http://amnis.revues.org/1606 y Raúl Mínguez, La paradoja católica ante la modernidad. Modelos de feminidad y mujeres católicas en España (1851-1874), Tesis doctoral, Universidad de Valencia, 2014 (especialmente cap. 3, 4, 5 y 8). Para el primer tercio del siglo Xx constituyen dos grandes aportaciones Inmaculada Blasco, Paradojas de la ortodoxia. Política de masas y militancia católica femenina en España (1919-1939), Prensas Universitarias de Zaragoza, Zaragoza, 2003 y Rebeca Arce, Dios, patria y hogar. La construcción social de la mujer española por el catolicismo y las derechas en el primer tercio del siglo XX, Universidad de Cantabria, Santander, 2007. 
existen trabajos que estudien la masculinidad liberal y, menos aún, la católica o antiliberal por lo que se hace necesario desarrollar la investigación en este campo durante los próximos años. ${ }^{49}$ Sí que se ha analizado, en cambio, el discurso de género del anticlericalismo liberal y republicano de finales del siglo XIX y principios del siglo XX, que estereotipó la figura de la beata como mujer sometida a los intereses de su confesor y que participó en el proceso de feminización discursiva del catolicismo para desprestigiarlo políticamente..$^{50}$

Si en el terreno discursivo, como vemos, todavía existen bastantes lagunas de conocimiento a pesar de su reciente dinamismo, en otros campos más clásicos de la tesis de la feminización religiosa el panorama no es mucho más halagüeño. Respecto a la práctica religiosa, resultan imprescindibles trabajos de carácter cuantitativo que sistematicen los datos dispersos que se poseen a nivel local y que, en efecto, sí parecen mostrar una preponderancia femenina. ${ }^{51}$ Sin embargo, las investigaciones no deberían centrarse únicamente en indicadores como la asistencia dominical a misa o la toma de comunión en Pascua sino tener en cuenta también otras esferas como las asociaciones de laicos, los periódicos o los partidos políticos en defensa de los intereses católicos, donde la pre-

49 Dos de los pocos trabajos que han tratado esta temática para el siglo XIX es Florencia Peyrou, «Familia y política: Masculinidad y feminidad en el discurso democrático isabelino», Historia y Política, 25, 2011, pp. 149-174. ... y María Sierra, género y emociones en el Romanticismo. El teatro de Bretón de los Herreros, Institución Fernando el Católico, Zaragoza, 2013, pp. 9-58. Para el primer tercio del siglo XX, deben destacarse los trabajos de Aresti, especialmente Nerea Aresti, Médicos, Donjuanes y Mujeres Modernas. Los ideales de feminidad y masculinidad en el primer tercio del siglo $\mathrm{XX}$, Universidad del País Vasco, Bilbao, 2001 y Nerea Aresti, Masculinidades en tela de juicio. Hombres y género en el primer tercio del siglo XX, Cátedra, Madrid, 2010.

50 María Pilar Salomón, «Las mujeres en la cultura política republicana: religión y anticlericalismo», Historia Social, 53, 2005, pp. 103-118 y María Pilar Salomón, «Devotas, mojigatas, fanáticas y libidinosas. Anticlericalismo y antifeminismo en el discurso republicano a fines del siglo XIX», en Ana Aguado y Teresa María Ortega (eds.), Feminismos y antifeminismos. Culturas políticas e identidades de género en la España del siglo XX, PUV, Valencia, 2011, pp. 71-98. Desde una perspectiva antropológica, Manuel Delgado, Las palabras de otro hombre. Anticlericalismo y misoginia, Muchnick Editores, Barcelona, 1993.

51 Así parecen confirmarlo algunos informes o relationes enviados por los obispos al Vaticano, como los remitidos por el obispo de Mallorca en 1876, por el arzobispo de Sevilla en 1893 y por el obispo de Madrid en 1922, o los datos sobre toma de la comunión en Pascua en algunas parroquias como la de Santiago el Real en Logroño. Información compilada en José Andrés-Gallego y Antón M. Pazos, La Iglesia en la España contemporánea 1 (1800-1936), Encuentro, Madrid, 1999, pp. 347, 350-351 y 375. 
sencia masculina fue mayoritaria. ${ }^{52}$ Además, tal como se ha señalado en el epígrafe anterior, no se puede perder de vista el trasfondo discursivo de la percepción extendida en la época de que las mujeres eran más religiosas que los hombres.

Aunque también sería necesario un estudio sistemático que aglutinara lo que ya se sabe a nivel local y regional, sí se pueden extraer algunas conclusiones de otro aspecto clásico de la feminización religiosa: la composición interna del clero. ${ }^{53}$ A partir de la observación del cuadro IV, podemos afirmar que el desarrollo congregacionista femenino en España guardó más semejanzas con el caso italiano que con el francés. Tras una primera mitad de siglo XIX dubitativa, el primer gran momento de auge congregacionista se produjo a partir de 1851, año en el que se firmó el Concordato entre el Gobierno español y la Santa Sede por el cual se estableció un marco legal favorable para las congregaciones femeninas -en su artículo 30 incentivaba el desarrollo de aquellas organizaciones religiosas femeninas dedicadas a la educación o a la caridad. El segundo momento destacado se iniciaría tras el Sexenio Democrático y perduraría hasta principios del siguiente siglo. De nuevo, la estabilidad política para la Iglesia, ahora asegurada por el régimen de la Restauración, fue un factor decisivo para que las congregaciones femeninas volvieran a florecer (más de un instituto fundado por año). Aunque las tres primeras décadas del siglo XX se caracterizaron por una cierta desaceleración en la fundación endógena de congregaciones, debemos tener en cuenta que este es el periodo en el que llegaron a España más congregaciones procedentes del extranjero, particularmente de Francia tras la aprobación de las leyes anticongregacionistas de la III República. De hecho, se llegaron a establecer

52 Aunque no fue planteada desde una perspectiva de género, la siguiente obra puede constituir un buen punto de partida: Begoña Urigüen, Orígenes y evolución de la derecha española: el neo-catolicismo, CSIC, Madrid, 1986. También desde los estudios biográficos pueden realizarse interesantes aportaciones en ese sentido, como las esbozadas en Juan Pro Ruiz, Bravo Murillo. Política de orden en la España liberal, Síntesis, Madrid 2006 o Carlos Mata, Francisco Navarro Villoslada (1818-1895) y sus novelas históricas, Gobierno de Navarra, Pamplona, 1995.

53 Además de los estudios concretos disponibles sobre algunas congregaciones, Cataluña es el territorio mejor conocido gracias a los trabajos de Ana Yetano: Ana Yetano, «Congregaciones religiosas femeninas. Algunos datos sobre el movimiento fundacional en Cataluña durante el siglo XIX», Anacleta sacra tarraconensia, 73, 2000, pp. 161-174 y Ana Yetano, «Con toca. Mujeres y trabajo hospitalario, avances en tiempos convulsos. Las hermanas de la caridad», Manuscrits, 27, 2009, pp. 113-139. 
41 congregaciones francesas entre 1901 y $1914 .{ }^{54}$ Finalmente, el tercer momento de esplendor fundador se produjo en el franquismo, un régimen de carácter confesional donde la institución eclesiástica gozó de numerosos privilegios. Durante los casi cuarenta años de dictadura franquista se fundaron cuarenta y cuatro nuevas congregaciones.

\section{Cuadro IV}

Fundación de congregaciones femeninas en España (1800-1975)

\begin{tabular}{lcc}
\hline Años & Número de fundaciones & Media anual \\
\hline $1800-1850 *$ & 13 & 0,25 \\
$1851-1860$ & 13 & 1,3 \\
$1861-1870$ & 6 & 0,6 \\
$1871-1880$ & 21 & 2,1 \\
$1881-1890$ & 13 & 1,3 \\
$1891-1900$ & 15 & 1,5 \\
$1901-1936^{*}$ & 27 & 0,75 \\
$1937-1975^{*}$ & 44 & 1,13 \\
\hline
\end{tabular}

Fuente: Elaboración propia a partir de varias referencias bibliográficas. ${ }^{55}$

* Sólo se recogen datos de las congregaciones dedicadas exclusivamente a la enseñanza o las dedicadas a trabajos mixtos (enseñanza y actividades asistenciales).

En términos cuantitativos y aun teniendo en cuenta las diferencias demográficas entre los tres países y la posible subrepresentación en el insuficientemente estudiado caso español, todo parece indicar que la fiebre fundacional en España fue menor que en Francia e Italia. Aunque a mediados

${ }^{54}$ Maitane Ostolaza, «Feminismo en religión: las congregaciones religiosas y la enseñanza de la mujer en España, 1851-1930», en María Concepción Marcos y Rafael Serrano (eds.), Mujer y política en la España contemporánea (1868-1936), Universidad de Valladolid, Valladolid, 2012, pp. 137-158 (dato en p. 139).

55 Jesús Martín Tejedor, Historia de las religiosas Siervas de San José (vol. I), Madrid, 1977, pp. 479-482; Vicente Faubell, «Las órdenes y congregaciones religiosas y la educación en la España contemporánea», en J.M. Prellezo (dir.), L'impegno dell'Educare, LAS, Roma, 1991, pp. 113-134 y Ángela del Valle, «Órdenes, congregaciones e institutos eclesiásticos femeninos dedicados a la educación y enseñanza», en Bernabé Bartolomé (dir.), Historia de la acción educadora de la Iglesia en España (vol. II), BAC, Madrid, 1996, pp. 512-718. 
del siglo XIX el número de monjas y congregacionistas era ya superior al de sus equivalentes masculinos por haber sufrido en menor medida las sucesivas exclaustraciones promovidas por los liberales, no fue hasta el cambio de centuria cuando el número de religiosas de vida activa superó al de religiosas de clausura. ${ }^{56}$ La mayor vitalidad interna del catolicismo francés y la poderosa presencia del papado en Italia pueden explicar parcialmente el menor desarrollo congregacionista del caso español. Sin embargo, no debemos olvidar que, salvo en momentos puntuales, España absorbió con éxito numerosas congregaciones procedentes de estos dos países.

La riqueza de la documentación personal (autobiografías, correspondencia, etc.) de algunas religiosas, especialmente de las superioras generales, ofrece un interesante campo de investigación que, sorprendentemente, se encuentra todavía prácticamente baldío a pesar de que este tipo de fuentes haya sido bastante trabajado en el caso de religiosas que vivieron en la Edad Media y Moderna. ${ }^{57} \mathrm{Su}$ análisis cualitativo puede ofrecer resultados muy interesantes relativos al problema de la capacidad de agencia de unas mujeres que, sin romper abiertamente con las estructuras de poder existentes, sí fueron capaces de aprovechar las posibilidades discursivas disponibles para desarrollar aspectos no comunes entre las mujeres de su época como la ambición, la autoridad y el liderazgo. ${ }^{58}$

Finalmente, en lo que respecta a la cuestión de la feminización de la piedad y la devoción religiosa, la mayoría de los estudios disponibles se han centrado especialmente en las apariciones y en las profecías. Según William Christian, los supuestos casos de apariciones divinas durante el siglo XIX y primeras décadas del XX no alcanzaron la repercusión y notoriedad de las ocurridas en Francia pero investigaciones recientes están lla-

56 Frances Lannon, Privilegio, persecución y profecía. La Iglesia Católica en España 1875-1975, Alianza, Madrid, 1990, pp. 81-112.

57 Una recopilación reciente de estudios sobre la Edad Moderna que analizan este tipo

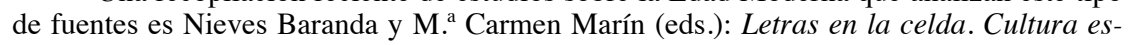
crita de los conventos femeninos en la España moderna. Iberoamericana, Madrid, 2014.

58 Sobre el tema de las congregaciones femeninas y de sus superioras generales me he concentrado más ampliamente en otros trabajos: Raúl Mínguez, «Una mujer entre Dios y el siglo: la Madre Sacramento», en María Isabel Morales, Marieta Cantos y Gloria Espigado (eds.), Resistir o derribar los muros. Mujeres, discurso y poder en el siglo XIX, Biblioteca Virtual Miguel de Cervantes, Alicante, 2014, pp. 105-116, edición digital: http://www. cervantesvirtual.com/obra/-8/ y Raúl Mínguez, «¿Fanáticas, maternales o feministas? Monjas y congregacionistas en la España decimonónica», Hispania Sacra (en prensa). También constituye un estudio interesante Mónica Moreno, «Religiosas, jerarquía y sociedad en España, 1875-1900», Historia Social, 38, 2000, pp. 57-71. 
mando la atención sobre el importante papel desempeñado por profetisas y videntes femeninas en contextos políticos conflictivos como la Guerra de la Independencia y la Segunda República. ${ }^{59}$ Quizás, la imagen más reiterativa en las visiones y apariciones fue la de la Virgen María, una figura cuyo poderoso simbolismo parece estar llamando la atención de varios historiadores desde puntos de vista diferentes. Por un lado, María representó, más que Eva, el modelo de feminidad católico en el siglo XIX. Obispos, sacerdotes y publicistas católicos trataron de mostrar a María como una madre humilde y abnegada, con preocupaciones que podían ser compartidas por las madres católicas decimonónicas. Pero, más allá de su contribución a la construcción de la diferencia sexual en la contemporaneidad, no debe olvidarse que la figura de María constituyó un instrumento de combate muy utilizado por un sector destacado del catolicismo en el conflictivo contexto político del siglo XIX. De hecho, no sólo contribuyó en su advocación de Inmaculada Concepción a la legitimación de la infalibilidad papal sino que también constituyó un efectivo instrumento de nacionalización utilizado por los católicos españoles en clave antiliberal. Un símbolo femenino pero utilizado mayoritariamente por hombres con fines políticos, así se puede resumir la complejidad de la figura de María en el siglo XIX. ${ }^{60}$

59 William A. Christian Jr., Moving crucifixes in modern Spain, Princeton University Press, Princeton, 1992; William A. Christian Jr., Visionaries. The Spanish Republic and the Reign of Christ, University of California Press, Los Angeles, 1996; Joseba Louzao: «La Virgen y la salvación de España. Un ensayo de historia cultural durante la Segunda República», Ayer, 82, 2011, pp. 187-210; Francisco Javier Ramón, «Persecución, milagros y profecías en el discurso católico zaragozano durante la Segunda República», Historia Social, 78, 2014, pp. 81-98; Francisco Javier Ramón, «Milagros, visiones apocalípticas y profecías. Una lectura sobrenatural de la Guerra de la Independencia», Ayer, 96, 2014, pp. 83-104 y Francisco Javier Ramón, «Una visionaria en las Cortes de Cádiz. Género y profecía en la crisis del Antiguo Régimen», en Ignacio Peiró y Mercedes Yusta (coord.), Heterodoxas, guerrilleras y ciudadanas. Formas de resistencia femenina en la España moderna y contemporánea, Institución «Fernando el Católico», Zaragoza, 2015, pp. 85-113.

60 Sobre la conexión de la figura de María y los procesos de nacionalización católicos, resultan muy interesantes Carolyn P. Boyd, «Paisajes míticos y la construcción de las identidades regionales y nacionales: el caso del santuario de Covadonga» en Carolyn P. Boyd (ed.), Religión y política en la España contemporánea, Centro de Estudios Políticos y Constitucionales, Madrid, 2007, pp. 271-294 y Francisco Javier Ramón, «La Virgen del Pilar dice...»Usos políticos y nacionales de un culto mariano en la España contemporánea. Prensas de la Universidad de Zaragoza, Zaragoza, 2014. En cuanto a los diversos significados adoptados por María en el conflictivo contexto del Bienio Progresista, puede consultarse Raúl Mínguez, «Las múltiples caras de la Inmaculada: religión, género y nación en su proclamación dogmática (1854)», Ayer, 96, 2014, pp. 39-60. 
Tras este sintético repaso de las aportaciones más interesantes sobre género y religión para el siglo XIX y primeras décadas del XX, el balance que se puede realizar es moderadamente optimista. Es verdad que existen todavía muchos terrenos de estudio todavía poco o insuficientemente trillados (la práctica religiosa, varios aspectos del fenómeno congregacionista, la contribución católica a la construcción de la masculinidad y feminidad contemporáneas, etc.) pero la aplicación de las innovaciones teóricas y metodológicas más recientes a nivel internacional por parte de un grupo dinámico de jóvenes historiadores del hecho religioso dibujan un panorama esperanzador. A mi juicio, el tema analizado en estas páginas es vital para comprender la compleja relación entre religión y modernidad, en el mundo occidental en general y en la España contemporánea en particular. La utilización de la categoría de género en los estudios sobre religión cuestiona la convicción ampliamente extendida de que el cristianismo, particularmente en su versión católica, adoptó una postura netamente antimoderna en la contemporaneidad. Los estudios más recientes no sólo demuestran la contribución de las diversas iglesias a la conformación de un modelo de feminidad que compartió muchos rasgos con el ángel del hogar liberal-burgués sino que además desmonta la teoría de que los hombres y la masculinidad permanecieran ajenos al hecho religioso. Así pues, el hecho cierto de que especialmente el catolicismo se opusiera a muchos elementos de la modernidad liberal-burguesa no implica que no utilizara algunos de sus mecanismos y de sus principios con los que desarrollar una vía diferente para acceder a la modernidad. 